\title{
Schizophrenia succeeded by affective illness: catamnestic study and statistical enquiry
}

\author{
C. SHELDRICK, A. JABLENSKY, N. SARTORIUS AND MICHAEL SHEPHERD ${ }^{1}$ \\ From the Institute of Psychiatry, London, and the Division of Mental Health, \\ World Health Organization, Geneva
}

SYNOPSIS On the basis of data derived from a long-term follow-up of 12 cases and a 2-year followup of the International Pilot Study of Schizophrenia it is suggested that some patients with remitting schizophrenic illnesses can subsequently present clear-cut affective disorders. The implications of these findings are discussed.

\section{INTRODUCTION}

Since the 1890s Kraepelin's dichotomous classification of the functional psychoses based on his description of the symptoms, course, and outcome of dementia praecox and manic-depressive psychosis has gained wide acceptance. Nonetheless, the limitations of this schema have been reflected by the many varied, and often elaborate, alternatives that have been proposed. A few workers have called for a revival of the preKraepelinian notion of the unitary psychosis; many more argue for the need to recognize a third group of functional psychoses, even though they disagree about its nature and its characteristics (Perris, 1974). One of their major points is the mixed picture of schizophrenic and affective symptoms exhibited by patients with socalled 'schizo-affective' disorders (Kasanin, 1933). Yet although from the clinical, genetic and statistical standpoints a degree of overlap between the two principal functional psychoses is well recognized, less consideration has been paid to the succession of one clinical condition by the other, the second illness or episode following the first after a period of remission and differing from it in respect of the clinical features.

Most experienced clinicians are familiar with a schizophrenic disorder which has been preceded by a manic-depressive illness or episode: a much-quoted study describing this phenomenon is that of Lewis \& Piotrowski (1954), who found

1 Address for correspondence: Professor Michael Shepherd, Institute of Psychiatry, De Crespigny Park, Denmark Hill, London SES 8AF. such a change in as many as $50 \%$ of their 122 patients. In contrast, however, as these authors pointed out, "very rarely is a schizophrenic reclassified as a manic-depressive psychotic'. This view has been generally accepted by AngloSaxon authors and conforms to the balance of opinion among German psychiatrists (Conrad, 1959). Nonetheless, the sequence of a schizophrenic illness followed by a manic-depressive psychosis has been documented in the literature (Juel-Nielsen \& Strömgren, 1963; Ziskind et al. 1971), though more often it has been ignored or even denied. The purpose of this paper is to draw attention to this phenomenon and to indicate its implications.

\section{METHOD}

\section{A. Catamnestic study}

Following the identification of 2 cases under the clinical care of one of the authors (M. S.) it was decided to search for comparable findings in the Professorial Unit follow-up records at the Maudsley Hospital. These records furnish regularly collected, standardized information about all in-patients who have entered the unit over the past 25 years. From the routine documentation it was possible to extract the records of all patients with a change in diagnosis over a period of at least 10 years following their index discharge. By collating the information derived from the follow-up records and the hospital case notes we were able to identify a group of 8 patients whose clinical picture and outcome rendered them eligible for inclusion by virtue of having 
suffered from a clear-cut schizophrenic illness followed, after a period of remission, by an unequivocally manic-depressive disorder. Two more cases were added from other units, making a total of 12 .

All the diagnoses had been made originally by the patients' physicians whose criteria were assessed retrospectively from the case-notes. The onset and phenomenology of discrete episodes were evaluated from notes taken both on admission and during the follow-up period. A diagnosis of schizophrenia was made on the basis of Eugen Bleuler's primary symptoms and/or the presence of Kurt Schneider's first rank symptoms. A diagnosis of affective disorder (manic-depressive psychosis) was made when schizophrenic symptoms were absent, and a disorder of affect alone was present (indicated by such phenomena as a morbid change in mood and psychomotor activity). Detailed case histories of all 12 patients are provided elsewhere (Sheldrick, 1975), but the history of one typical case may be summarized as an example:

Mr J. M., garage attendant, aged 31, one of 2 children. His sister had received out-patient treatment for depression and frigidity. She was described as having 'a long-standing neurotic personality'. The paternal grandfather had possibly suffered from a schizophrenic illness, and a paternal aunt had been institutionalized for such a condition from the age of 38 . The patient was regarded as a solitary person who had experienced particular difficulties with his superiors at work. This partly explained his many changes of occupation, usually as a shop or garage assistant. He had married at the age of 21 and had 2 children; the eldest child (aged 7) was showing signs of disturbed behaviour.

The patient was first seen as an out-patient aged 16 , complaining that for several months his senior at work had been arranging things to test him out, e.g. changing initials in messages that he had to deliver. He had been sitting at home, at times laughing and weeping and at times asking his mother whether he was a homosexual or a sex maniac. On examination he appeared puzzled and mildly suspicious, with some flattening of affect. His talk was vague, with some thought-blocking and although denying hallucinations he admitted to ideas of reference and to the possibility that his thoughts were being interfered with. A diagnosis of 'probable schizophrenia' was made at the time. Treatment with trifluoperazine was commenced, to good effect. Tricyclic antidepressants were added after 2 months and cessation of both drugs after a further 4 months precipitated a relapse necessitating hospital admission (aged 17). On this occasion he was restless and aggressive. He denied being ill and was diagnosed as suffering from paranoid schizophrenia; he made a good response to trifluoperazine. He continued on phenothiazines and was readmitted to hospital twice, aged 18 and 22: his main symptoms were flatness of affect and thought disorder, a diagnosis of schizophrenia being made on both occasions.

At the age of 23 he became depressed, took an overdose of tablets and was admitted to hospital. On examination he showed no vagueness, thought disorder or other psychotic symptoms. He was then regarded as suffering from depression and was treated with tricyclic medication only. He was readmitted to hospital on 3 more occasions (aged 24, 25 and 26), each time with hypomanic illnesses, though these were variably associated with depressive symptomatology and some persecutory ideas. The response to phenothiazines and tricyclic medication was good and he was put on to lithium carbonate at the age of 27 since when he has remained well save for episodes of mild depression and anxiety when he required additional medication on an out-patient basis.

\section{B. IPSS study}

Having established this pattern retrospectively in an unselected group of patients we were concerned to obtain an estimate for its frequency. For the purpose, it becomes necessary to have access to a homogeneous cohort of patients, preferably followed up prospectively over a uniform period of time. Such a population was obtainable from the International Pilot Study of Schizophrenia (IPSS). This transcultural psychiatric investigation of more than 1000 patients in 9 countries is sponsored jointly by the World Health Organization, the US National Institute of Mental Health and various field research centres, and has been well documented (World Health Organization, 1973). It has included an initial examination and follow-up reassessments of the patient cohorts after 2 and 5 years, all based on standardized methods. Material from the 2-year follow-up study was utilized for this enquiry.

\section{RESULTS}

\section{A. Catamnestic study}

All 12 patients had been diagnosed as unequivocally schizophrenic at the time of their 


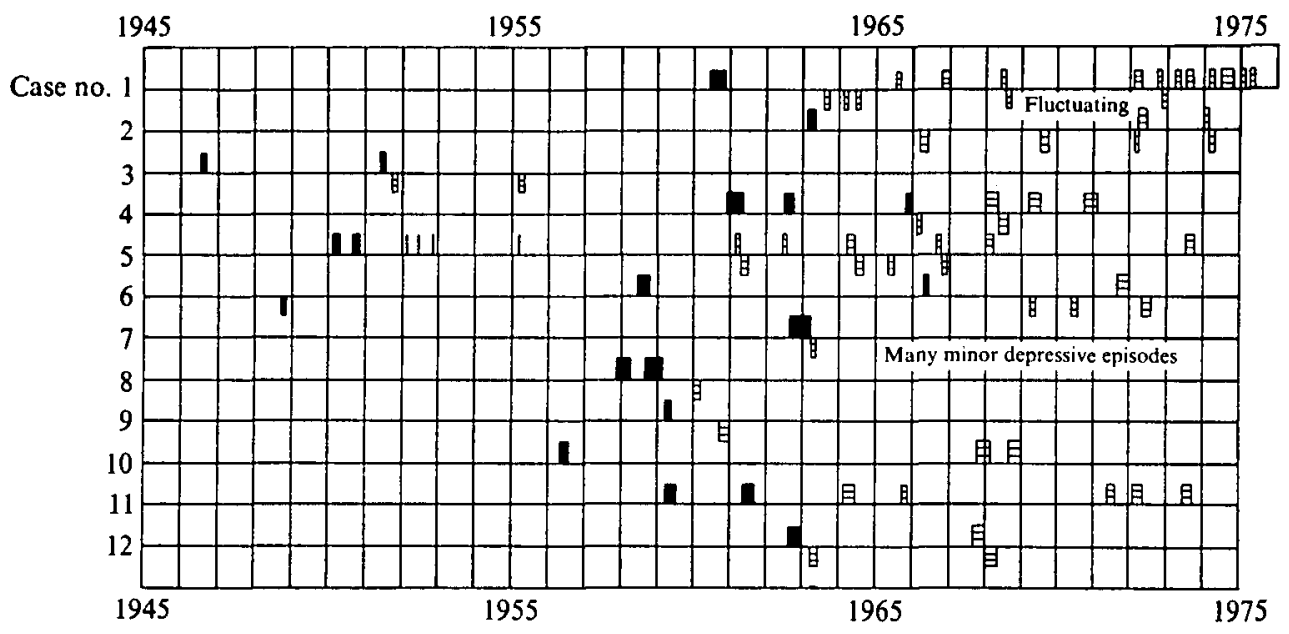

Schizophrenia

Hypomania 且目 Depression

Fig. 1. Diagnostic outcome of 12 patients.

index admission. Characteristic symptoms had included the presence of paranoid delusions in every case, passivity and/or thought interference phenomena in 7 cases and catatonic features in 5 cases. The paranoid delusions had been persecutory in 10 patients, involving poisoning by drugs or rays, or the spreading of malicious gossip with a consequent fear of death or change of sex. The grandiose delusions recorded in 5 patients had been religious in nature, and in 3 cases were accompanied by persecutory delusions. The passivity phenomena had involved a range of 'influence', some unspecified and others attributable to devils, God, rays and television. The patients with catatonic features had presented varying pictures of posturing, indifference to external events or negativistic behaviour; 2 of them required tube-feeding.

All these patients had a history of short-lived schizophrenic episodes with brief durations of hospital treatment, except for one illness which had led to a 10 months stay in hospital. The recorded prognoses on most cases was poor and an unsatisfactory outcome would have resulted from the application of Vaillant's predictive scoring method (Vaillant, 1964).

From Fig. 1 it can be seen that on follow-up the episodes of manic-depressive psychosis were generally discrete and of short duration, occurring after remission from the earlier schizophrenic illnesses. It is also noteworthy that they included both hypomanic and depressive episodes. Further, although both forms of disordered mood were recorded in individual cases, there was no instance of a schizophrenic illness returning after remission had been interrupted by an affective episode.

A careful search in the records for particular features which might help account for this unsuspected outcome proved unrewarding. There was nothing atypical in the clinical picture, age of onset, co-existent or past physical illness, or family history.

\section{IPSS study}

Of the original IPSS patients with clinical diagnoses of schizophrenia or affective psychosis, complete follow-up information was available on 570 of the 811 schizophrenics and 122 of the 164 cases with affective disorders. This included a detailed assessment of the course and clinical state 2 years after the initial examination. Altogether 608 schizophrenic and 139 affective patients were examined at follow-up but some were excluded from this analysis because of missing items of information. In toto, 
Table 1. IPSS schizophrenic patients by type of course over a 2-year period

\begin{tabular}{ccc}
\hline & \multicolumn{2}{c}{ Schizophrenia } \\
\cline { 2 - 3 } & No. & $\%$ \\
\hline Remitting & 422 & 74 \\
Non-remitting & 148 & 26 \\
Total & 570 & 100 \\
\hline \hline
\end{tabular}

Table 2. IPSS remitting schizophrenic patients by occurrence of relapses over a 2-year period

\begin{tabular}{ccc}
\hline & \multicolumn{2}{c}{ Remitting schizophrenia } \\
\cline { 2 - 3 } & No. & $\%$ \\
\hline No relapses & 251 & 60 \\
Relapses & 171 & 40 \\
Total & 422 & 100 \\
\hline
\end{tabular}

Table 3. IPSS remitted and relapsing schizophrenic patients by occurrence of change in symptomatology

\begin{tabular}{lrr}
\hline \hline & $\begin{array}{c}\text { Remitted and relapsing } \\
\text { schizophrenia }\end{array}$ \\
\cline { 2 - 3 } & No. & $\%$ \\
\hline Symptom change & 39 & 23 \\
No symptom change & 132 & 77 \\
Total & 171 & 100 \\
\hline \hline
\end{tabular}

more than $80 \%$ of all patients were successfully followed up. One half of the remainder could be traced but were not reassessed for various reasons; their diagnostic category, age and sex distribution did not differ significantly from that of the total patient series.

Tables 1, 2 and 3 show the number and proportion of schizophrenic patients in terms of outcome over the 2-year follow-up period. Twenty-nine patients developed at least one unequivocal affective episode during this time after a clear period of remission. This constitutes $3 \%$ of the total cohort and $17 \%$ of those patients who remitted and subsequently relapsed.

The psychiatrists participating in the IPSS all used a standardized method of diagnosis with a high level of reliability in their clinical assessments. Further, the material was also processed by a computer program (CATEGO) which employs uniform rules and definitions.
Of the 171 relapsing schizophrenics $132(77 \%)$ fell into CATEGO Class $\mathrm{S}$ (schizophrenic psychoses with delusions and characteristic auditory hallucinations, or other symptom patterns commonly encountered in schizophrenia). Of the 29 patients who had relapses of an affective type 15 were placed in this category.

\section{DISCUSSION}

Various factors must be taken into account when attempting to evaluate these findings. One well-recognized cause for a change in diagnosis over time is inaccuracy in the recording of symptoms. This has been demonstrated experimentally and can apply to recordings made by either several observers or by the same observer on different occasions (Shepherd et al. 1968). In one relevant study Cooper (1967) concluded that while a change of psychiatric diagnoses in hospital records was most commonly attributable to a change in doctor, the degree of refinement in the categories employed was also significant: whereas, for example, only $20 \%$ of patients proved to have retained their diagnoses when expressed as 4-digit ICD categories, the proportion rose to $54 \%$ when eight large groupings were used.

Interpretation can also be determined by preconceptions concerning the nature of the schizophrenias. Within the broad category of the functional psychoses there has been widespread implicit and explicit agreement with the statement that the diagnosis of manic-depressive psychosis can be made only by the elimination of schizophrenia ... even a trace of schizophrenia is schizophrenia and has very important prognostic significance' (Lewis \& Piotrowski, 1954). This view, which underlies the allocation of schizo-affective disorder to the category of schizophrenia in the ICD, assumes a hierarchical ordering of phenomena whereby affective symptoms are 'weighted' less heavily than those which are classically associated with schizophrenia. At the same time a better prognosis is also associated with affective symptomatology. Those workers who have described but discounted a change in diagnosis from schizophrenia to manic-depressive psychosis are evidently influenced by this way of thinking. Riser et al. (1961), for example, have introduced the concept of an 'atypical' depressive equiva- 
lent to schizophrenia, while Kirov \& Tsvetkova (1974) and Taylor \& Abrams (1975) have suggested that schizophrenics who developed subsequent affective episodes were suffering from an affective disorder $a b$ initio.

The hierarchical principle, which underlies the DIAGNO II and SAID computer diagnostic programs, has also been adopted by Ollerenshaw (1973), though he inverts it to diagnose schizophrenia only after excluding underlying organic and manic-depressive disease viewing much of what is generally termed acute schizophrenia as symptomatic of an affective illness.

An expansive use of the concept of 'schizoaffective' illness has been advocated by other clinicians (Vaillant, 1963) to accommodate cases which cannot be fitted comfortably into either of the 2 main categories. However, this would be difficult to support in the light of the present case-material, for although some of the patients presented affective symptoms at the time of the index illness, there was never an initial diagnosis of schizo-affective disorder. Furthermore, Vaillant's cases made an unheralded change from schizophrenia to manic-depressive psychosis without passing through an intermediate phase of remission. Nonetheless some psychiatrists are of the opinion that over the years there has been an amelioration in the presenting symptoms, the nature of the relapses and the residual symptoms and signs of schizophrenia which may or may not be related to medication. Hare (1974) has even suggested that a mild recurrence of a schizophrenic illness might express itself as an affective disturbance.

Patients who almost immediately on recovery from an acute schizophrenic illness develop a typical endogenous depression have been well documented (Bowers \& Astrachan, 1966; Steinberg et al. 1967; Roth, 1970; McGlashan \& Carpenter, 1976). Such cases are not usually diagnosed as schizo-affective. In recent years the sequence has often been regarded as a transient reaction state preceding recovery or has been often ascribed to the use of depot phenothiazine preparations (Alarcón \& Carney, 1969; Johnson, 1969; Marjot, 1969). There is, however, ample evidence in the literature to show that this transition was recognized and recorded before the advent of phenothiazines. When considering the data presented in this paper we can reasonably exclude artefact or methodological bias. The cases were assessed and diagnosed independently by different clinicians at different times. The sequence of episodes summarized in Fig. 1 illustrates clearly the interval between the 2 types of disorder, the multiplicity of affective episodes and the high proportion of hypomanic as well as depressive phenomena. For all these reasons the change in the pattern of illness cannot be attributed to medication.

The clinical findings are supported by the results of the IPSS. In this enquiry the diagnostic preconceptions were largely eliminated, the study was prospective and the assessments were rendered as objective as possible. Here again it emerges that a proportion of patients diagnosed as suffering from schizophrenia developed clearcut affective illnesses after a period of remission from the original psychotic episode. A closer examination of the CATEGO $S$ schizophrenic patients who subsequently developed affective episodes indicated that, together with symptoms characteristic of schizophrenia, they tended to exhibit some affective symptoms such as change in mood or sleep disturbance. It may be that, though the initial diagnosis of schizophrenia in these patients was unquestionable, the patients showed symptomatological differences from the remaining schizophrenics in the study. Because of the small numbers involved, however, it was not possible to investigate this issue statistically.

Finally, mention should be made of the implications of these suggestive findings. Evidence in favour of a clear change from schizophrenic to manic-depressive symptomatology carries significance for the disease entity theory and for the classification of the functional psychoses as a whole. The establishment of such a sequence argues against an absolute separation of the 2 major groupings, indicating as it does the possibility of a 'metamorphosis' of one disorder into another. The logic here is independent of the existence of the disputed schizoaffective psychosis or of other 'atypical' functional psychoses or of possible drug-effects; nor can it be related to the postulated sequence of syndromes in the various stages of development of schizophrenia (Snezhnevsky, 1972). It suggests rather that some at least of the categories within the congeries of schizophrenic and affective disorders are not mutually exclusive. In so doing it revives the issue of the "unitary psychosis' raised by Zeller (1837) and Griesinger 
(1845) and more recently discussed by Rennert (1965). Kraepelin himself in his later writings was more open-minded than is generally acknowledged about the possibility of affective episodes occurring within the course of some schizophrenias. However, it may be emphasized that in our material the sequence was unidirectional: there was no single instance of a patient reverting to a schizophrenic syndrome after having relapsed with affective symptoms. The hypothesis that one 'disease entity' can be replaced by another would be confirmed if it could be demonstrated that both the original and subsequent conditions satisfy the respective criteria of the postulated 'entities'. The 5-year follow-up of the IPSS should furnish crucial information on this question.

\section{REFERENCES}

Alarcón, R. de \& Carney, M. (1969). Severe depressive mood changes following slow-release intra-muscular fluphenazine injection. British Medical Journal iii, 564-567.

Bowers, M. \& Astrachan, B. (1966). Depression in acute schizophrenic psychosis. American Journal of Psychiatry 123, 976-979.

Conrad, K. (1959). Das Problem der 'nosologischen Einheit' in der Psychiatrie. Der Nervenarzt 30, 488-494.

Cooper, J. E. (1967). Diagnostic change in a longitudinal study of psychiatric patients. British Journal of Psychiatry 113, 129-142.

Griesinger, W. (1845). Pathologie und Therapie der psychischen Krankheiten. Stuttgart.

Hare, E. H. (1974). The changing content of psychiatric illness. Journal of Psychosomatic Research 18, 283-289.

Johnson, J. (1969). Depressive changes after fluphenazine treatment. British Medical Journal iii, 718.

Juel-Nielsen, N. \& Strömgren, E. (1963). Five years later. Acta Jutlandica 25, 1. Universitetsfarlaget i Aarhus, Munksgaard.

Kasanin, J. (1933). The acute schizo-affective psychoses. American Journal of Psychiatry 90, 97-126.

Kirov, K. \& Tsvetkova, S. (1974). A study of manic-depres- sive patients presenting with 'schizophrenic' symptomatology. Nevrologija, Psikiatrija, Nevrokirurgija (Sofia) 13, 146-152.

Lewis, N. \& Piotrowski, Z. (1954). Clinical diagnosis of manic-depressive psychosis. In Depression (ed. P. M. Hoch and J. Zubin). Grune \& Stratton: New York.

Marjot, D. (1969). Depression following fluphenazine treatment. British Medical Journal iii, 780.

McGlashan, T. \& Carpenter, W. (1976). Post-psychotic depression in schizophrenia. Archives of General Psychiatry 33, 231-239.

Ollerenshaw, D. (1973). The classification of the functional psychoses. British Journal of Psychiatry 122, 517-530.

Perris, C. (1974). A study of cycloid psychoses. Acta Psychiatrica Scandinavica, Suppl. 253. Munksgaard.

Rennert, H. (1965). Die Universalgenese der endogenen Psychose. Fortschritte der Neurologie, Psychiatrie und ihrer Grenzgebiete 33, 251-272.

Riser, M., Laboucarié, J., Peyrevidal-Lacassin, A. \& Lacassin, P. (1961). Formes atypiques et méconnues de la mélancholie. Annals Médico-psychologiques 119, 417-446.

Roth, S. (1970). The seemingly ubiquitous depression following acute schizophrenic episodes, a neglected area of clinical discussion. American Journal of Psychiarry 127, 51-58.

Sheldrick, C. (1975). The validity of the distinction between schizophrenia and manic-depressive psychosis. M.Phil. thesis, University of London.

Shepherd, M., Brooke, E., Cooper, J. \& Lin, T. (1968). An experimental approach to psychiatric diagnosis. Acta Psychiatric Scandinavica, Suppl. 201. Munksgaard.

Snezhnevsky, A. V. (ed.) (1972). Schizophrenia: a multidisciplinary investigation. Meditzina. Moscow.

Steinberg, H., Green, R. \& Durell, J. (1967). Depression occurring during the course of recovery from schizophrenic symptoms. American Journal of Psychiatry 124, 699-702.

Taylor, M. \& Abrams, R. (1975). Manic-depressive psychosis and good prognosis schizophrenia. American Journal of Psychiatry 132, 741-742.

Vaillant, G. (1963). The natural history of the remitting schizophrenias. AmericanJournal of Psychiatry 120, 367-375.

Vaillant, G. (1964). Prospective prediction of schizophrenic remission. Archives of General Psychiatry 11, 509-518.

World Health Organization (1973). The International Pilot Study of Schizophrenia, vol. 1. WHO: Geneva.

Zeller, E. (1837). Bericht über die Wirksamkeit der Heilanstalt Winnenthal von ihrer Eröffnung den 1 März bis zum 28 Februar 1837. Medizinisches Correspondenzblatt des würtembergischen ärztlischen Vereins 7, 321.

Ziskind, E., Somerfeld, E. \& Jens, R. (1971). Can schizophrenia change to affective psychosis? American Journal of Psychiatry 138, 331-335. 